\title{
Caracterização dos Lineamentos Magnéticos da Região Central da Bacia do Paraná
}

Carreira, V. R. 1, La Terra, E. F. 2, Fontes, S. L. 3 ; 1, 2, 3 Observatório Nacional, Rio de Janeiro, Brasil.

Copyright 2014, SBGf - Sociedade Brasileira de Geofísica.

Este texto foi preparado para a apresentação no VI Simpósio Brasileiro de Geofísica, Porto Alegre, 14 a 16 de outubro de 2014. Seu conteúdo foi revisado pelo Comitê Técnico do VI SimBGf, mas não necessariamente representa a opinião da SBGf ou de seus associados. É proibida a reprodução total ou parcial deste material para propésitos comerciais sem prévia autorizaç ão da SBGf.

\section{Resumo}

Este trabalho tem como objetivo estudar os lineamentos magnéticos observados na parte central da bacia do Paraná, em complementação a estudos magnetotelúricos que estão sendo promovidos pela Agência Nacional do Petróleo - ANP. E, o objetivo é descobrir qual a tendência principal de lineamentos estruturais, na região do levantamento MT. O estudo das grandes estruturas do embasamento de bacias sedimentares são de suma importância tanto para o entendimento de sua evolução tectônicoestratigráfica, quanto para o estudo dos sistemas petrolíferos. A Bacia do Paraná, em especial, é uma bacia rasa, com depocentro estimado em $6000 \mathrm{Km}$. Grandes derrames de lava são representados pela Formação Serra Geral, que, fornece a energia necessária para a maturação da matéria orgânica, existente nos principais plays exploratórios. E, estas intrusões aproveitaram os determinados grupos de lineamentos estruturais pretéritos para poderem se instalar. Para que fosse possível estudar as direções principais desses lineamentos, realizou-se uma pesquisa de dados potenciais pré-existentes, tendo em vista que sua aplicação é bem consolidada na análise de grandes estruturas do embasamento de bacias sedimentares. Neste trabalho, em especial, são apresentados dados potenciais magnéticos da região de estudo.

\section{Introdução}

A Bacia do Paraná é classificada como uma bacia cratônica marginal com domínio flexural de crosta. Está localizada no centro-sul da América do Sul. O seu formato é ovalado e irregular, a sua extensão, em área, abrange cerca de $1.100 .000 \mathrm{Km}^{2}$. (Milani, 1998)

A maior porção de sua área está contida no Brasil. Contudo, a bacia abrange os países Paraguai, Uruguai e Argentina. A porção brasileira abrange os estados do Rio Grande do Sul, Santa Catarina, Paraná, Mato Grosso, Mato Grosso do Sul, Goiás, São Paulo, e Minas Gerais. (Milani and Ramos, 1998)

A geologia delimita tectonicamente a bacia na borda nordeste pelo arco do Alto Parnaíba que possui direção NW-SE; na borda leste pelo Arco de Ponta-Grossa; na borda Sul o Arco do Rio Grande, que une-se com em sua extensão noroeste com o Arco de Assunção, dando origem a borda oeste; a borda noroeste é limitada pelo Arco de
São Vicente. (Zalan, 1987). Dentre os principais grupos de estruturas são notáveis três grupos de lineamentos: NWSE, E-W, NE-SW. Cada grupo representante de um evento termo-tectônico distinto. O conjunto de lineamentos NWSE são os mais antigos e estão relacionados ao evento termo-tectônico do Transamazônico, e, as zonas de falhas geológicas associadas a este evento foram reativadas durante o rifteamento do Atlântico Sul, no Cretáceo. Os lineamentos E-W, tiveram início a partir do Triássico e são paralelos às zonas de fratura oceânica, o que sugere uma ligação com o desenvolvimento do Atlântico Sul. Os lineamentos NE-SW são derivados do evento tremo-tectônico Brasiliano e de seus cinturões móveis associados. Este último conjunto de lineamentos são isentos de diques de basalto. (Borghi, 2002) apud (Milani, 1999). Em termos de sistemas petrolíferos convencionais, os principais plays exploratórios são bem conhecidos na literatura científica. São estes: o sistema petrolífero Ponta Grossa - Itararé/Rio Bonito; e o sistema petrolífero Irati - Rio Bonito/Pirambóia. As rochas geradoras desses sistemas são, respectivamente o folhelho Ponta Grossa e o folhelho Irati. E, seus reservatórios são, respectivamente os diamictitos do Grupo Itararé e os arenitos da Formação Rio Bonito e, no segundo sistema petrolífero, novamente os arenitos da Formação Rio Bonito e os arenitos da Formação Pirambóia. E, por fim, a os basaltos e diabásios da Formação Serra Geral encerram as principais rochas que compõem os sistemas petrolíferos da Bacia. (Zalan, 1987) (França, 1991)

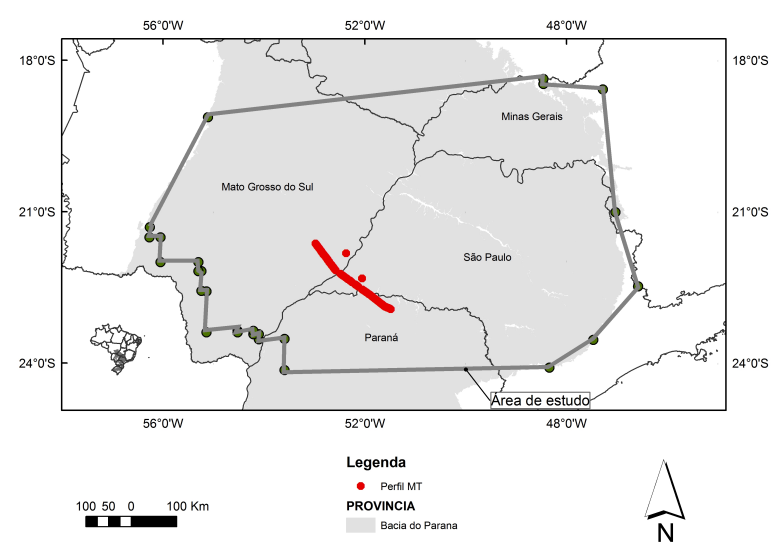

Figura 1: Localização da área de estudo. Os pontos em vermelho representam o perfil MT realizado na Bacia. Os dois pontos vermelhos fora da linha são as localizações das estações de referência remota.

A região de estudo, propriamente dita, ocupa a porção 
central da Bacia do Paraná, entre os paralelos geográficos $19^{\circ} 30^{\prime}$ e $24^{\circ} 30^{\prime} \mathrm{S}, 56^{\circ} 30^{\prime}$ e $47^{\circ} 00^{\prime} \mathrm{W}$. Os dados são oriundos do aerolevantamento magnetométrico 9.123/08ANP-004.952 realizado entre 6 de abril de 2009 até 23 de maio de 2010.

O objetivo deste trabalho é contribuir com informações importantes sobre as principais direções dos conjuntos de lineamentos que existem na área de estudo. Para tal foram elaborados mapas de anomalia magnética residual, TMI (Total Magnetic Intensity), ASA (amplitude do sinal analítico), mapas de derivadas direcionais, mapa das profundidades das fontes magnéticas causativas de anomalia (Blakely, 1996) calculadas a partir da deconvolução de Euler. Por fim, foram elaborados um estereograma, um diagrama de roseta com a frequência desses lineamentos e um histograma mostrando as principais direções existentes da região de estudo.

\section{Metodologia}

A metodologia de trabalho foi dividida em duas etapas distintas. A primeira destas foi a etapa de préprocessamento dos dados. Nesta etapa, os dados foram reprocessados afim de remover os erros sistêmicos. Foram realizadas as operações de correção da variação diúrna, remoção do IGRF, paralax, Lag. E, por fim, os dados foram nivelados e micro nivelados. O método de interpolação bi-direcional foi utilizado em todas as etapas do trabalho. A etapa de pré-processamento seguiu conforme o organograma abaixo.

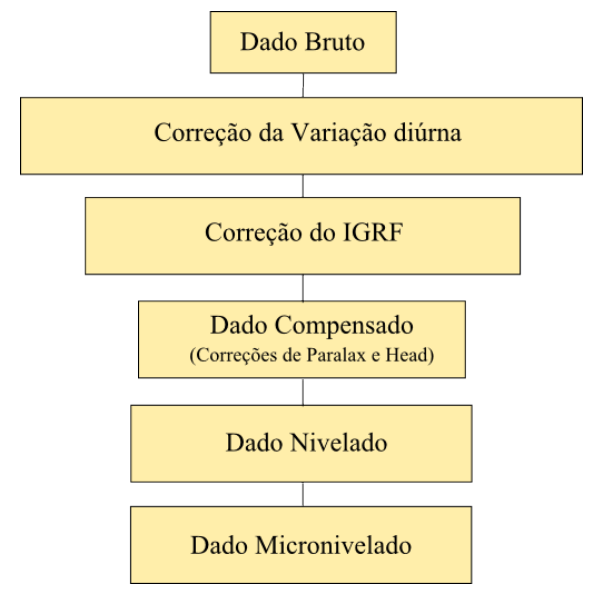

Figura 2: Etapas de pré-processamento.

Ao término de cada etapa do pré-processamento os dados eram interpolados e submetidos a inspeção visual para a remoção de artefatos criados por erros sistêmicos, advindos do aerolevantamento. Tais como, o efeito magnético da aeronave nos dados, o efeito das linhas de amarração e os efeitos da irregularidade das linhas de voo.

O Mapa a seguir apresenta o resultado do procedimento de pré-processamento.

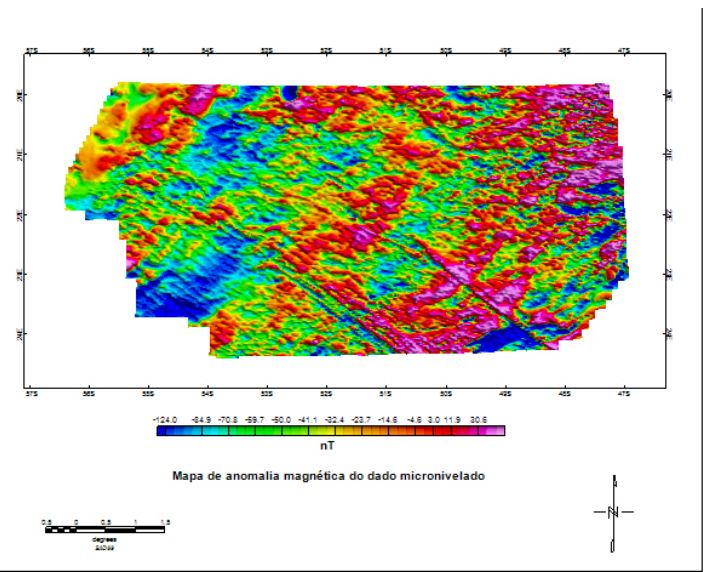

Figura 3: Mapa de anomalia magnética micronivelado.

A segunda etapa da metodologia de trabalho trata-se da fase de processamento do dado propriamente dito, que varia de acordo com a natureza do dado geomagnético. No caso específico, foram realizados o cálculo do TIM, Total Magnetic Intensity, remoção de fontes regionais através do ajuste por um polinômio do $1 \mathrm{grau}$, em seguida aplicou-se de um filtro de frequência passabaixa de primeira ordem para filtrar os comprimentos de onda curtos ocasionados por anomalias magnéticas próximas à superfície. Posteriormente, foram realizadas as operações de derivações nas três direções $\frac{\partial M}{\partial x}, \frac{\partial M}{\partial y}, \frac{\partial M}{\partial z}$. $E$, em seguida foram analisadas a amplitude do sinal analítico (ASA), e, por fim, aplicada a deconvolução de Euler. A organograma a seguir mostra a sequência de processamento tomada.

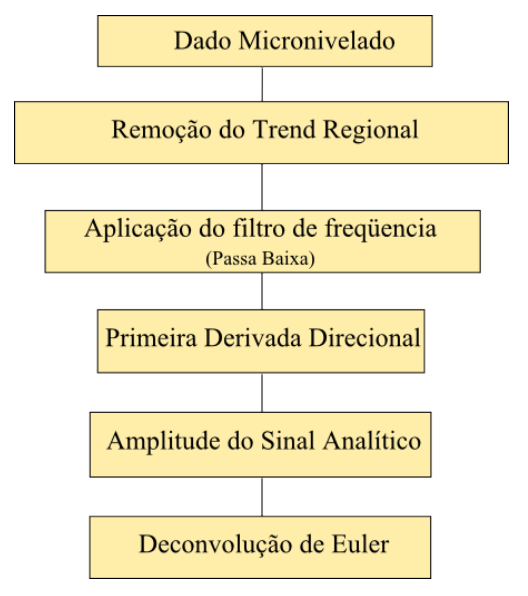

Figura 4: Organograma de processamento

\section{Resultados}

A análise das primeiras derivadas direcionais permitem uma análise geométrica, que indicam mudanças no declive do campo magnético. Foi realizada uma análise de cada componente separadamente. Posteriormente foi realizado o cálculo do gradiente horizontal, que nada mais é do que a combinação das derivadas parciais nas direções $x$ e $y$ da anomalia do campo magnético $M$, (Ferreira, 2010). Como é mostrado a seguir: 


$$
G H=\sqrt{\left(\frac{\partial M}{\partial x}\right)^{2}+\left(\frac{\partial M}{\partial y}\right)^{2}}
$$

O Gradiente Horizontal é comumente utilizado para delinear os limites dos corpos e das estruturas causadoras das principais anomalias. A medida que se aumenta a ordem das derivadas aumenta-se 0 detalhamento das estruturas, contudo são igualmente realçados os ruídos(Ferreira, 2003). Portanto, optou-se pela utilização das derivadas direcionais $x \mathrm{e} z$.

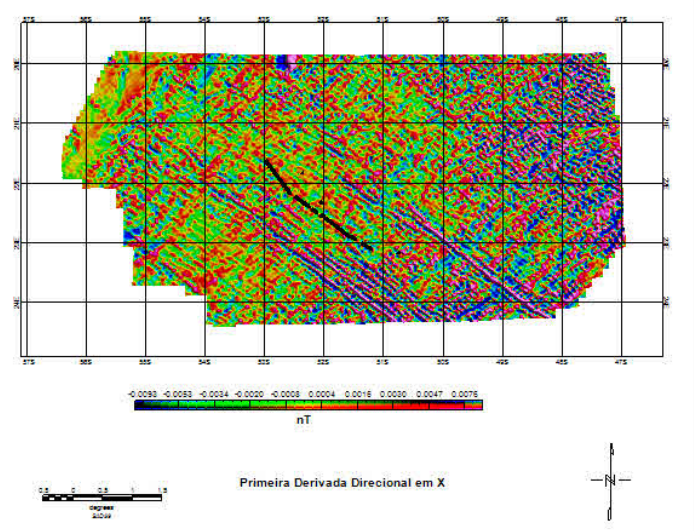

Figura 5: Derivada horizontal de primeira ordem, com o perfil magnetotelúrico, em preto.

O mapa de derivada direcional de primeira ordem em $x$ deixa em evidência duas linhas de estruturas predominantes: uma NW-SE e outra NE-SW. Indicando que ambos os conjuntos de lineamentos refletem estruturas a nível da bacia sedimentar.

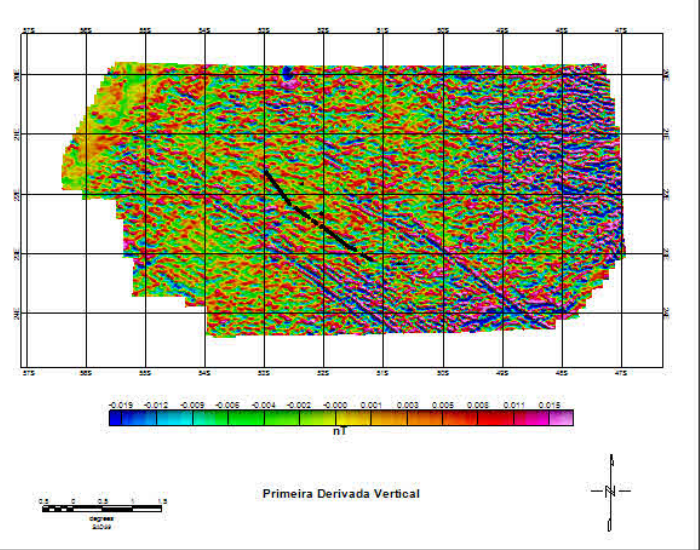

Figura 6: Mapa de derivada vertical, com o perfil magnetotelúrico, em preto.

O mapa de derivada direcional de primeira ordem em $z$ evidencia as estruturas de direção NW-SE em relação as estruturas de direção NE-SW. Este comportamento é indicativo de que a fonte do sinal magnético NW-SE é mais profunda e reflete estruturas do embasamento da bacia sedimentar. (Ferreira, 2010)
O mapa de amplitude do sinal analítico é o que melhor permite, a delimitação de corpos como um todo no espaço. Pois, este leva em consideração as derivadas horizontais $(\partial x, \partial y)$ e vertical $(\partial z)$. No caso de estruturas 2D, o método assume que as fontes apresentam magnetização uniforme e podem ser representadas por seções transversais de polígonos. Estas estruturas podem ser consideradas superposições de um certo número de contatos magnéticos. (Hsu, 1996)

$\mathrm{Na}$ análise 3D, a amplitude do sinal analítico pode ser definida simplesmente como a resultante da soma das duas componentes reais na direção $x, y$ e uma componente imaginária $z$. (Barbosa, 2013)

$$
A S A=\sqrt{\left[\left(\frac{\partial M}{\partial x}\right)^{2}+\left(\frac{\partial M}{\partial y}\right)^{2}+\left(\frac{\partial M}{\partial z}\right)^{2}\right]}
$$

Seu gráfico é uma função simétrica em formato de sino, com o seu máximo localizado exatamente sobre o topo de cada contato, e sua largura está relacionada diretamente com a profundidade do corpo gerador da anomalia. (Nabighian, 1974)

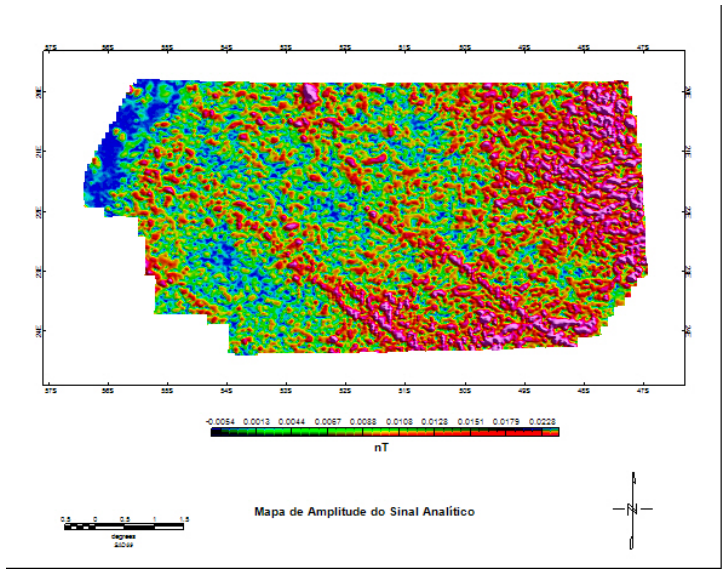

Figura 7: Amplitude do Sinal Analítico.

O mapa de amplitude do sinal analítico, mostrado na figura 7 , indica corpos profundos e com direções preferenciais NW-SE em maior escala, e, em menor escala corpos mais rasos de direção E-W. 


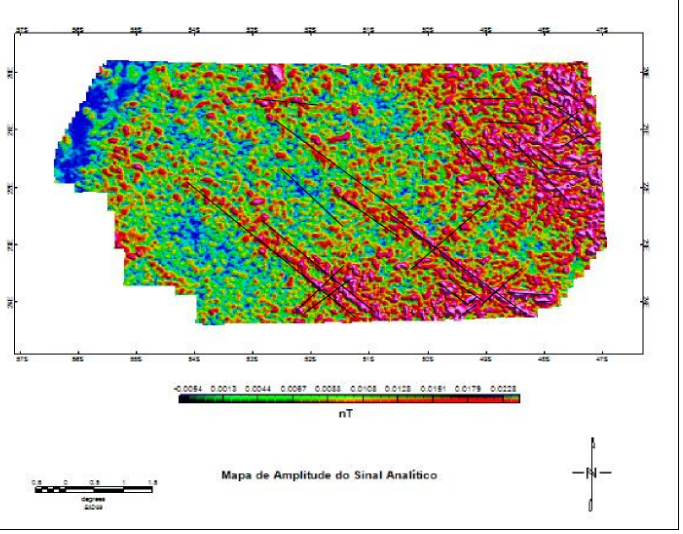

Figura 8: Principais Lineamentos Magnéticos de escala regional.

A partir da figura 7 foi possível traçar os principais lineamentos mais evidentes da área de estudo, figura 8. $E$, a partir dessa inferência se tornou possível medir os azimutes e elaborar um estereograma com as principais direções de lineamentos, figura 9.

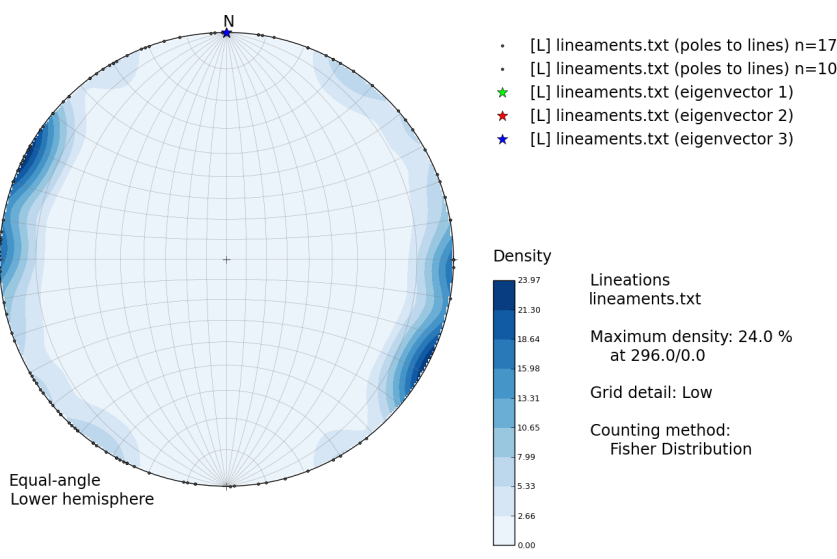

Figura 9: Direções dos strikes magnéticos.

As medidas dos azimutes magnéticos plotados no estereograma indicam uma concentração de pontos nas direções NW-SE e E-W. E, o diagrama de roseta de comprimento de frequência indica uma direção em destaque com direção N65W.

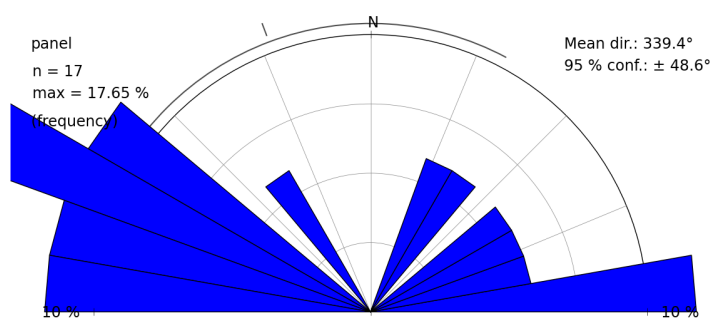

Figura 10: Diagrama de Roseta de frequência.

O histograma dos lineamentos magnéticos apresentou uma distribuição bimodal com valores máximos no conjunto amostral entre $275^{\circ}$ e $325^{\circ}$.

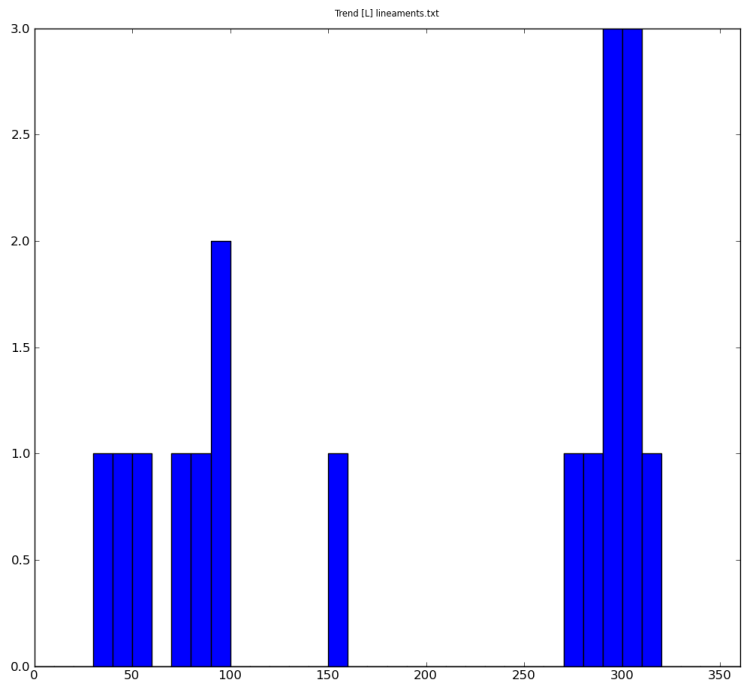

Figura 11: Histograma com os principais lineamentos

O espectro de potência radial indica fontes rasas que apresentam profundidades máximas variando entre 3 a 2.5 $\mathrm{km}$. 


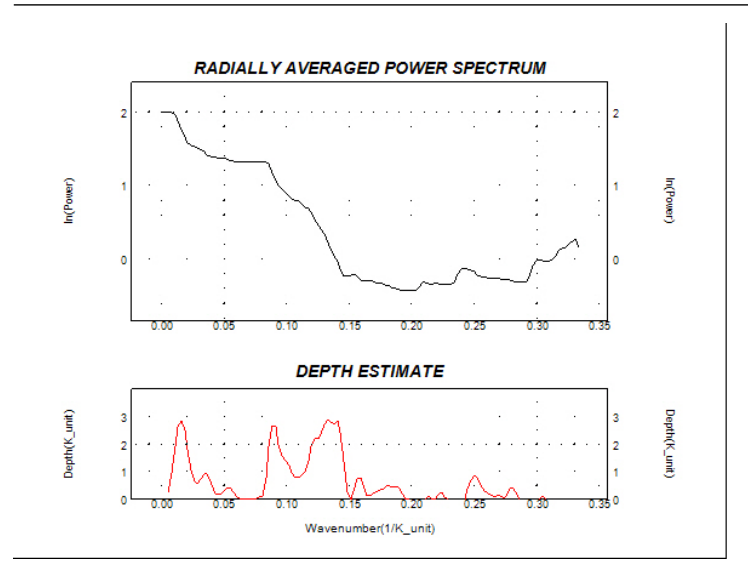

Figura 12: Espectro de Potência Radial

A deconvolução de Euler é amplamente aplicada na interpretação magnética, pois não necessita de um conhecimento da geometria da fonte e do vetor de magnetização. (Tompson, 1982). O método que se baseia na aplicação da equação homogênea de Euler, relaciona o campo potencial e seus gradientes para localizar a fonte, com base no grau de homogeneidade $\eta$. Este grau é interpretado como o índice estrutural, que está relacionado com a natureza da fonte, derivando-se com uma janela móvel com $\eta$ fixo, a posição e a profundidade dos corpos.(Ferreira, 2003). Uma aproximação geométrica padrão para diques e soleiras é a de um prisma tabular. Um prisma tabular possui um valor de Índice Estrutural igual a $1(\eta=1)$. Através do mapa de pontos de Euler foi possível estimar profundidades do topo das principais fontes magnéticas presentes na região. (Tompson, 1982)

O método de deconvolução de Euler é dado pela equação:

$$
\left(x-x_{o}\right) \frac{\partial M}{\partial x}+\left(y-y_{o}\right) \frac{\partial M}{\partial y}-\left(z-z_{o}\right) \frac{\partial M}{\partial z}=\eta(B-M)
$$

Onde $\left(x_{o}, y_{o}, z_{o}\right)$ são as coordenadas do campo magnético $M$ e o seu valor regional $B$ são medidos no ponto $(x, y, z)$ e $\eta$ é dado como o grau de homogeneidade que está relacionado com o índice estrutural. (Abreu, 2013)

O Mapa de pontos da deconvolução de Euler mostra uma preponderância de fontes rasas de até $3 \mathrm{~km}$ corroborando com as profundidades estimadas no espectro de potência radial.

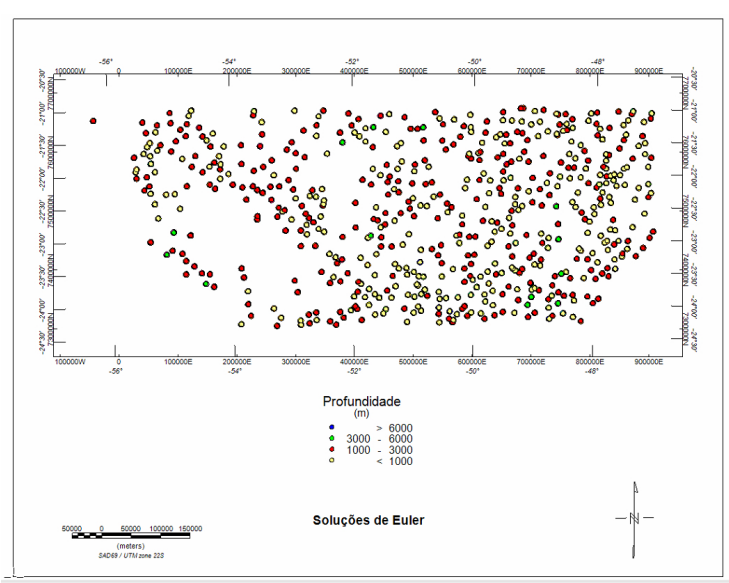

Figura 13: Mapa de soluções de Euler.

\section{Conclusões}

É notável mediante as figuras 9,10 e 11 que a região central da Bacia do Paraná apresenta lineamentos com direções preferenciais NW-SE, que são as mesmas direções dos lineamentos Transamazônicos que foram reativados durante a fase de abertura do Atlântico Sul com a intrusão de diques e soleiras de basalto e diabásio. De acordo com os mapas de derivadas direcionais de primeira ordem, figuras 5 e 6, e com o mapa de amplitude do sinal analítico - ASA, figura 7, essas feições NWSE são detectáveis tanto em profundidade relacionadas ao embasamento da bacia, quanto em profundidades relacionadas aos sedimentos da bacia.

O espectro de potência radial juntamente com o mapa de soluções de Euler, figuras 12 e 13, indicam de uma maneira regional fontes magnéticas rasas.

\section{Agradecimentos}

Os autores agradecem à ANP por ter cedido os dados, ao Observatório Nacional pelo fornecimento das instalações de pesquisa. E, Victor Ribeiro Carreira agradece ao CNPq pela concessão bolsa de mestrado, e o Dr. Sergio Luiz Fontes pela concessão da bolsa de Produtividade em Pesquisa. 


\section{Referências}

Abreu, C.J., e. F. H., 2013, Considerações sobre a configuração estrutural da bacia do parecis apartir da análise de dados aeromagnéticos: Presented at the Thirteenth International Congress of the Brazilian Geophysical Society.

Barbosa, V. C. F., 2013, Estimating the nature and the horizontal and vertical positions of 3D magnetic sources using euler deconvolution: Geophysics, 78, 87-98.

Blakely, J. B., 1996, Potential theory in gravity and magnetic applications.: Cambrigde University Press New York, 2nd, 441p.

Borghi, L., 2002, Fácies, arquitetura deposicional, tempestitos e o devoniano da bacia do paraná: PhD thesis, Universidade Federal do Rio de Janeiro.

Ferreira, F., 2003, Processamento e interpretação de dados aeromagnéticos da região central do arco de ponta grossa (bacia do paraná).

Ferreira, F.J.F. e Romeiro, M. A. T., 2010, Realce do gradiente horizontal de anomalias magnéticas usando a inclinação do sinal analítico. parte i - aplicação de dados sintéticos.: 6.

França, A. B. e Potter, P. E., 1991, Stratigraphy and reservoir potential of glacial deposits of the itarare group (carboniferous-permian), parana basin, brazil (1): AAPG Bulletin, 75, 62-85.

Hsu, S. K., 1996, High-resolution detection of geologic boundaries from potential-field anomalies: An enhanced analytic signal technique: 61, 13 .

Milani, E. J., and V. A. Ramos, 1998, Orogenias paleozóicas no domínio sul-ocidental do gondwana e os ciclos de subsidência da bacia do paraná: Brazilian Journal of Geology, 28, 473-484.

Milani, E. J. e Zalan, P. V., 1999, An outline of the geology and petroleum systems of the paleozoic interior basins of south america: Episodes, 22, 199-205.

Milani, E. J. e Ramos, V. A., 1998, Orogenias paleozóicas no domínio sul-ocidental do gondwana e os ciclos de subsidência da bacia do paraná: Brazilian Journal of Geology, 28, 473-484.

Nabighian, M., 1974, The analytic signal of two dimentional magnetic bodies with poligonal crosssection: its properties and used for automated anomaly interpretation.

Tompson, D., 1982, Euldph: A new technique for making computer assisted depth estimates from magnetic data.: Geophysics, 47, 31-37.

Zalan, P. V. e Wolf, S., 1987, Tectônica e sedimentação da bacia do paraná: , $36 \mathrm{p}$. 